\title{
Increased tissue kallikrein levels in type 2 diabetes
}

\author{
D. J. Campbell • A. Kladis • Y. Zhang • A. J. Jenkins • \\ D. L. Prior • M. Yii • J. F. Kenny • M. J. Black • \\ D. J. Kelly
}

Received: 20 October 2009 / Accepted: 30 November 2009 / Published online: 10 January 2010

(C) Springer-Verlag 2009

\begin{abstract}
Aims/hypothesis We measured components of the kallikreinkinin system in human type 2 diabetes mellitus and the effects of statin therapy on the circulating kallikrein-kinin system. Methods Circulating levels of bradykinin and kallidin peptides, and high and low molecular weight kininogens, as well as plasma and tissue kallikrein, and kallistatin were measured in non-diabetic and diabetic patients before coronary artery bypass graft surgery. Tissue kallikrein levels in atrial tissue were examined by immunohistochemistry and atrial tissue kallikrein mRNA quantified.
\end{abstract}

Electronic supplementary material The online version of this article (doi:10.1007/s00125-009-1645-8) contains supplementary material, which is available to authorised users.

D. J. Campbell $(\bowtie) \cdot$ A. Kladis $\cdot$ D. L. Prior

St Vincent's Institute of Medical Research,

41 Victoria Parade,

Fitzroy, Victoria 3065, Australia

e-mail: dcampbell@svi.edu.au

D. J. Campbell $\cdot$ Y. Zhang $\cdot$ A. J. Jenkins $\cdot$ D. L. Prior · D. J. Kelly

Department of Medicine, University of Melbourne,

St Vincent's Health,

Fitzroy, Victoria, Australia

\section{L. Prior}

Department of Cardiology, St Vincent's Health,

Fitzroy, Victoria, Australia

\section{Yii · J. F. Kenny}

Department of Cardiothoracic Surgery, St Vincent's Health,

Fitzroy, Victoria, Australia

M. J. Black

Department of Anatomy and Developmental Biology,

Monash University,

Clayton, Victoria, Australia
Results Plasma levels of tissue kallikrein were approximately $62 \%$ higher in diabetic than in non-diabetic patients $(p=0.001)$, whereas no differences were seen in circulating levels of bradykinin and kallidin peptides, and high and low molecular weight kininogens, or in plasma kallikrein or kallistatin. Immunohistochemistry revealed a twofold increase in tissue kallikrein levels in atrial myocytes $(p=$ 0.015), while tissue kallikrein mRNA levels were increased eightfold in atrial tissue of diabetic patients $(p=0.014)$. Statin therapy did not change any variables of the circulating kallikrein-kinin system. Neither aspirin, calcium antagonists, beta blockers or long-acting nitrate therapies influenced any kallikrein-kinin system variable.

Conclusions/interpretation Tissue kallikrein levels are increased in type 2 diabetes, whereas statin therapy does not modify the circulating kallikrein-kinin system. Cardiac tissue kallikrein may play a greater cardioprotective role in type 2 diabetic than in non-diabetic patients and contribute to the benefits of ACE inhibitor therapy in type 2 diabetic patients. However, our findings do not support a role for the kallikrein-kinin system in mediating the effects of statin therapy on endothelial function.

Keywords Aldosterone - Angiotensin - Bradykinin · Immunohistochemistry $\cdot$ Kallidin $\cdot$ Kallikrein $\cdot$ Kallistatin . Kininogen $\cdot$ Statin $\cdot$ Type 2 diabetes

$\begin{array}{ll}\text { Abbreviations } \\ \text { ARB } & \text { Angiotensin type 1 receptor blocker } \\ \text { CABG } & \text { Coronary artery bypass graft } \\ \text { HMWK } & \text { High molecular weight kininogen } \\ \text { Hyp } & \text { Hydroxyproline } \\ \text { KBK } & \text { Kallidin; lysine }{ }^{0} \text {-bradykinin } \\ \text { KKS } & \text { Kallikrein-kinin system }\end{array}$


LMWF Low molecular weight fluorophore

NT-proBNP Amino-terminal-pro-B-type natriuretic peptide

\section{Introduction}

The kallikrein-kinin system (KKS) has a broad spectrum of actions that encompass inflammation and organ protection. Kinin peptides contribute to the actions of ACE inhibitors and angiotensin type 1 receptor blocker (ARB) therapies [1]. In diabetes, the KKS may contribute to increased endothelial permeability, glomerular hyperfiltration and glomerular injury, but may also play a critical role in organ protection $[2,3]$. ACE is one of the main pathways of kinin metabolism, and clinical and animal studies show an association between $A C E$ gene polymorphisms associated with increased ACE activity and increased diabetic complications $[4,5]$. Moreover, ACE inhibition increases kinin levels [6] and reduces diabetic complications [7]. Increased kinin levels may also contribute to the reduction of diabetic complications by ARB therapy $[8,9]$.

We previously reported increased kinin levels in heart, aorta and kidney of streptozotocin-induced diabetic rats [10]. We therefore examined the hypothesis that diabetes increases the activity of the KKS in human type 2 diabetes. We studied patients scheduled for coronary artery bypass graft (CABG) surgery, because they routinely have short radial arterial cannulae inserted before surgery, which assists rapid blood collection with minimal kallikrein activation. In addition, we obtained samples of right atrial appendage from some patients to perform immunohistochemistry for tissue kallikrein and to measure tissue kallikrein mRNA levels. Because a large proportion of these patients were receiving 3-hydroxy-3-methylglutarylcoenzyme A reductase inhibitor (statin) therapy, and because statin therapy affects endothelial function and possibly also kinin generation at the endothelial surface $[11,12]$, the association between current statin use and KKS variables was also evaluated.

\section{Methods}

Patients The St Vincent's Health Human Research Ethics Committee approved this study and all patients gave written informed consent. This study was performed in a convenience sample of patients with coronary artery disease scheduled for CABG surgery. We excluded patients scheduled for other cardiac surgical procedures such as valve surgery, patients with heart failure or receiving furosemide therapy, patients with left ventricular ejection fraction $<50 \%$ and patients with serum creatinine $>0.16 \mathrm{mmol} / \mathrm{l}$. Two groups of patients were recruited. Group 1 patients were recruited from 1998 to 2006. During this time ACE inhibitor or ARB therapies for type 2 diabetic patients were not routine and we excluded patients receiving either of these therapies. In the early stages of patient recruitment it was standard practice for elective patients to be requested to cease aspirin therapy 2 weeks before surgery and to cease statin therapy 1 week before surgery, unless surgery was urgent or the surgeon specifically requested continuation of these therapies. Patients who ceased aspirin or statin therapy $\geq 7$ days before surgery were recorded as not taking these medications for the purpose of these analyses. Of the 59 group 1 patients, 53 had stable coronary artery disease and six had recently experienced a non-ST segment elevation myocardial infarction. The mean known duration of diabetes for group 1 diabetic patients was 6.7 years (range 123 years). Of diabetic patients, five received diet alone as diabetes therapy, three received insulin alone, two received metformin alone, six received metformin and a sulfonylurea, and four received a sulfonylurea alone. Only one nondiabetic patient was on fibrate therapy. $\mathrm{HbA}_{1 \mathrm{c}}$ was measured in eight diabetic patients (mean 8.5\%, range 5.7-13.8\%).

Group 2 consisted of an additional 12 patients recruited from 2005 to 2006 for the study of tissue kallikrein in atrial tissue. At this time, essentially all diabetic patients were receiving ACE inhibitor or ARB therapy, statin therapy was no longer routinely ceased before surgery, and it was more common for patients on aspirin to continue this therapy until surgery. All group 2 patients had stable coronary artery disease. The mean duration of diabetes for group 2 diabetic patients was 9 years (range $1-25$ years). Of the five diabetic patients, one was being treated with diet alone, two were on insulin alone, one on metformin alone, and one on metformin and a sulfonylurea. $\mathrm{HbA}_{1 \mathrm{c}}$ was measured in three of the five diabetic patients (mean 7.6\%, range 5.3$9.8 \%$ ). In addition to collection of blood before anaesthesia, the right atrial appendage was collected from group 2 patients at surgery during cannulation for cardiopulmonary bypass.

Biochemistry All blood samples were collected from the radial artery cannula of fasted patients before anaesthesia. Blood haemoglobin and $\mathrm{HbA}_{1 \mathrm{c}}$, and plasma levels of glucose, insulin, lipids and creatinine were measured by St Vincent's Health Pathology using routine clinical methods. GFR was calculated from the modification of diet in renal disease formula [13]. HOMA of insulin resistance (HOMA2-IR), insulin sensitivity (HOMA2-\%S) and beta cell function (HOMA2-\%B) were calculated using the HOMA calculator version 2.2 [14]. Carboxymethyl lysine was measured by ELISA (Microcoat, Penzberg, Germany). Low molecular weight fluorophore (LMWF) levels were measured by fluorescence spectroscopy [15]. Plasma aldosterone was measured by radioimmunoassay 
(Coat-a-Count; Diagnostics Products, Los Angeles, CA, USA). Amino-terminal-pro-B-type natriuretic peptide (NTproBNP) was measured by electrochemiluminescence immunoassay using an Elecsys instrument (Roche Diagnostics, Basel, Switzerland).

Measurement of angiotensin, bradykinin and kallidin peptides Blood was collected into plastic syringes from a three-way tap close to the arterial cannula in order to avoid activation of kallikrein during blood sampling. For measurement of angiotensin and bradykinin peptides, $2 \mathrm{ml}$ blood was immediately transferred to a tube containing $10 \mathrm{ml} 4 \mathrm{~mol} / \mathrm{l}$ guanidine thiocyanate and 1\% (vol./vol.) trifluoroacetic acid, and mixed thoroughly. For measurement of kallidin peptides, $10 \mathrm{ml}$ blood was immediately transferred to a tube containing $20 \mathrm{ml} 1 \mathrm{~mol} / \mathrm{l} \mathrm{HCl}$. The guanidine thiocyanate/trifluoroacetic acid and $\mathrm{HCl}$ blood samples were processed and assayed as described previously using HPLC-based RIA [16]. These assays enabled specific measurement: (1) of the bradykinin peptides bradykinin-(1-9), hydroxyproline (Hyp) ${ }^{3}$-bradykinin-(1-9), bradykinin-(1-8), Hyp ${ }^{3}$-bradykinin-(1-8), bradykinin-(1-7) and $\mathrm{Hyp}^{3}$-bradykinin-(1-7); and (2) of the kallidin peptides lysine ${ }^{0}$-bradykinin (KBK)-(1-9), Hyp ${ }^{3}-\mathrm{KBK}-(1-9)$, KBK(1-8), Hyp ${ }^{3}-$ KBK-(1-8), KBK-(1-7) and Hyp ${ }^{3}-\mathrm{KBK}-(1-7)$. Non-hydroxylated and hydroxylated peptides were summed to simplify presentation of kinin peptide levels.

Measurement of plasma levels of kininogen, plasma and tissue kallikrein, and kallistatin Blood for measurement of plasma concentrations of kininogens, plasma and tissue kallikrein, and kallistatin was collected into heparinised tubes, immediately centrifuged $(1,780 \times g)$ and the plasma snap-frozen in dry ice. Plasma levels of high molecular weight kininogen (HMWK) and low molecular weight kininogen were measured by an enzymatic method [17]. Plasma levels of total plasma kallikrein were measured by western blot analysis of non-reduced plasma samples run on 5 to $15 \%$ gradient SDS-PAGE and probed with monoclonal antibody 13G11 (QED Bioscience, San Diego, CA, USA) [18]. This antibody recognises plasma prekallikrein and active plasma kallikrein. In normal plasma, plasma kallikrein circulates predominantly as the zymogen prekallikrein [19] and migrates as two species with predicted size of 85 and $88 \mathrm{kDa}$. Thus, migration on SDS-PAGE does not allow differentiation of the zymogen from active kallikrein. Kallistatin levels were measured by western blot analysis of reduced plasma samples run on 5 to $15 \%$ gradient SDS-PAGE and probed with monoclonal antibody G4C10 (a gift from J. Chao, Medical University of South Carolina, Charleston, SC, USA) [20]. Kallistatin migrates with a predicted size of approximately $58 \mathrm{kDa}$. Plasma levels of total tissue kallikrein were quantified by western blot analysis of reduced plasma samples run on $5 \%$ to $15 \%$ gradient SDS-PAGE. Western blots were probed for total tissue kallikrein using a polyclonal antibody (antiTproK-AS) raised against recombinant human tissue prokallikrein (a gift from M. Kemme, Technische Universität Darmstadt, Darmstadt, Germany) [21]. This antibody recognises tissue prokallikrein and active tissue kallikrein. Tissue prokallikrein and active tissue kallikrein migrate with a predicted size of approximately $34 \mathrm{kDa}$, so migration on SDS-PAGE does not allow differentiation of the zymogen from active kallikrein. Detection was by chemiluminescence and films were quantified by densitometry. Each western blot contained samples from one to two nondiabetic patients not taking statins, one to two non-diabetic patients taking statins, one to two diabetic patients not taking statins, and one to two diabetic patients taking statins. For each western blot, densitometry data were expressed as the percentage of the mean value for the nondiabetic patients not taking statins, set at $100 \%$.

Tissue prokallikrein immunohistochemistry Right atrial tissue obtained at surgery from group 2 patients was immediately rinsed in ice-cold saline with $20 \mathrm{mmol} / \mathrm{l} \mathrm{KCl}$ then placed in $10 \%$ (vol./vol.) buffered formalin overnight before paraffin embedding. Immunohistochemistry was performed with the same antibody used for western blotting for tissue kallikrein: anti-TproK-AS [21]. Immunostaining was quantified using computer-assisted image analysis and expressed as the percentage area of immunostaining.

Real-time quantitative PCR Right atrial tissue obtained at surgery from group 2 patients was immediately rinsed in ice-cold saline with $20 \mathrm{mmol} / 1 \mathrm{KCl}$ then rapidly frozen in liquid nitrogen and stored at $-80^{\circ} \mathrm{C}$. After thawing at $-20^{\circ} \mathrm{C}$ in RNAlater-ICE (Ambion, Austin, TX, USA), RNA was extracted with a mini-kit (RNeasy Fibrous Tissue kit; Qiagen Pty Ltd, Doncaster, VIC, Australia) and reverse-transcribed with a kit (Quantitect; Qiagen Pty Ltd). Human tissue kallikrein mRNA was measured by TaqMan gene expression assay (catalogue number: Hs00158490_m1; Applied Biosystems, Foster City, CA, USA) with a device (Rotor Gene RG-3000; Qiagen Pty Ltd) and quantified by the comparative cycle threshold method using the ribosomal protein L41 as reference (catalogue number: Hs00606029_g1; Applied Biosystems) as validated by Barth et al. [22].

Statistical analysis Continuous data were analysed by oneway or two-way ANOVA, with logarithmic transformation of data when necessary to normalise data distribution and variances, except for mRNA data, which were analysed by permutation test. Categorical data were analysed by Fisher's exact test. All tests were two-tailed. Differences were considered significant at $p<0.05$. 
Power calculation For the comparison of the means of two groups with SD of approximately one-half the mean for each group ( $\alpha=0.05), 20$ participants in each group would be required to detect a $50 \%$ difference in mean values with $87 \%$ power (JMP 7.0; SAS Institute, Cary, NC, USA). The power for a two-way ANOVA is similar for each main effect, where ten participants in each of the four groups (20 participants exposed to each main effect) would achieve similar power, as calculated with the SAS macro program, fpower.sas (www.math.yorku.ca/SCS/Online/power/, accessed 13 December 2009). For the bradykinin data, where the number of participants in each group was seven to 16 , the effect of diabetes involved a comparison of 27 nondiabetic and 16 diabetic patients, and the effect of statin therapy involved a comparison of 20 patients not taking, and 23 patients taking, statins. Thus, for bradykinin levels, where the SD was approximately one-half the mean for each group, our study had approximately $90 \%$ power to detect a $50 \%$ difference in bradykinin levels in response to diabetes or statin therapy. The power to detect differences was correspondingly less for variables measured in fewer participants.

\section{Results}

Clinical characteristics We studied two groups of patients. Group 1 comprised 39 non-diabetic and 20 diabetic patients (Electronic supplementary material [ESM] Table 1). None of the group 1 patients was receiving ACE inhibitor or ARB therapies, because we have shown that these therapies increase blood bradykinin levels [6,9]. In addition, we excluded patients with heart failure or significantly impaired left ventricular function, because we had previously shown that heart failure is associated with suppressed blood kallidin levels [16]. Group 1 patients were predominantly men and diabetic patients were more likely than nondiabetic patients to have hypertension. However, group 1 patients were well matched for age, BMI, pre-operative blood pressure, smoking status, renal function, NT-proBNP levels and cardiovascular therapies, with the exception that patients on statins were more likely to be also taking aspirin and calcium antagonists, and had a slightly lower haemoglobin level.

Random and fasting glucose levels were elevated in group 1 diabetic patients (ESM Table 1). There was no difference in fasting plasma insulin levels between nondiabetic and diabetic patients, although diabetic patients had reduced beta cell function. Diabetic patients had lower LDL-cholesterol concentrations, and total and LDLcholesterol concentrations were reduced in patients receiving statins. Plasma carboxymethyl lysine and LMWF levels were not different between non-diabetic and diabetic patients. Plasma aldosterone concentrations were similar for non-diabetic and diabetic patients, but were reduced in patients receiving statins. Not all KKS variables were measured in all patients. Blood kallidin levels were measured in fewer patients than angiotensin and bradykinin peptide levels because of sample loss during the initial kallidin assays and the need to recruit additional patients for kallidin peptide measurement.

Group 2 comprised seven non-diabetic and five diabetic patients who were all receiving ACE inhibitor or ARB therapy, with none receiving both. The characteristics of non-diabetic and diabetic patients of group 2 were similar except for higher fasting plasma glucose and LMWF levels in diabetic patients (ESM Table 2). Most (80-86\%) were receiving statin therapy.

Blood levels of angiotensin, bradykinin and kallidin peptides Neither diabetes nor statin therapy affected angiotensin, bradykinin, kallidin or kininogen concentrations, except for a lower angiotensin I concentration in diabetic patients (Table 1). Separate analyses showed that aspirin, calcium antagonist, beta blocker or long-acting nitrate therapies had no effect on blood angiotensin, bradykinin or kininogen levels. Patient numbers were insufficient to assess the effects of other drug therapies on blood kallidin levels.

Plasma levels of kininogens, plasma and tissue kallikreins, and kallistatin Neither diabetes nor statin therapy was associated with alteration in plasma kallikrein or kallistatin levels (Table 1). By contrast, diabetes was associated with a $62 \%$ increase in plasma levels of tissue kallikrein $(p=$ 0.001 ), although statin therapy did not significantly affect that variable. Separate analyses showed that aspirin, calcium antagonist, beta blocker or long-acting nitrate therapies had no effect on plasma levels of plasma kallikrein, kallistatin or tissue kallikrein.

Tissue kallikrein immunohistochemistry and mRNA levels in atrial tissue Immunohistochemistry showed tissue kallikrein predominantly in atrial myocytes, with an approximately twofold greater immunoreactivity in diabetic than in nondiabetic patients $(p=0.015$; Fig. 1). Quantitative PCR showed an eightfold increase in tissue kallikrein mRNA in atrial tissue of diabetic patients (ratio to control: $1.0 \pm 0.1$, $n=7$ vs $8.0 \pm 3.8, n=5, p=0.014)$.

\section{Discussion}

We report for the first time the effects of type 2 diabetes on the KKS in humans. We found increased levels of tissue kallikrein as evidenced by increased circulating levels of tissue kallikrein, increased tissue kallikrein immunoreactiv- 
Table 1 Blood levels of angiotensin, bradykinin and kallidin peptides, and plasma levels of kininogens, plasma and tissue kallikreins, and kallistatin in group 1 patients who were non-diabetic or diabetic, and not receiving or receiving statin therapy

\begin{tabular}{|c|c|c|c|c|c|c|c|}
\hline \multirow[t]{2}{*}{ Variables } & \multicolumn{2}{|c|}{ Non-diabetic } & \multicolumn{2}{|l|}{ Diabetic } & \multicolumn{3}{|c|}{ Effects ( $p$ values) } \\
\hline & No statin & Statin & No statin & Statin & Diabetes & Statin & Interaction \\
\hline Tested for Ang and BK peptides $(n)$ & 11 & 16 & 9 & 7 & & & \\
\hline Ang II (pmol/l) & $1.5 \pm 0.4$ & $1.4 \pm 0.4$ & $1.5 \pm 0.6$ & $0.7 \pm 0.2$ & NS & NS & NS \\
\hline Ang I (pmol/l) & $1.5 \pm 0.5$ & $1.9 \pm 0.4$ & $1.4 \pm 0.5$ & $0.5 \pm 0.1$ & 0.04 & NS & NS \\
\hline Ang II/Ang I ratio (mol/mol) & $2.3 \pm 0.9$ & $1.0 \pm 0.2$ & $1.1 \pm 0.3$ & $1.4 \pm 0.5$ & NS & NS & NS \\
\hline $\mathrm{Hyp}^{3}-\mathrm{BK}+\mathrm{BK}-(1-7)(\mathrm{pmol} / \mathrm{l})$ & $2.1 \pm 0.5$ & $2.1 \pm 0.2$ & $2.3 \pm 0.4$ & $2.1 \pm 0.4$ & NS & NS & NS \\
\hline $\mathrm{Hyp}^{3}-\mathrm{BK}+\mathrm{BK}-(1-8)(\mathrm{pmol} / \mathrm{l})$ & $1.3 \pm 0.2$ & $1.4 \pm 0.3$ & $1.2 \pm 0.2$ & $1.3 \pm 0.3$ & NS & NS & NS \\
\hline $\mathrm{Hyp}^{3}-\mathrm{BK}+\mathrm{BK}-(1-9)(\mathrm{pmol} / \mathrm{l})$ & $2.4 \pm 0.5$ & $3.3 \pm 0.6$ & $3.0 \pm 0.7$ & $2.7 \pm 0.7$ & NS & NS & NS \\
\hline Tested for kallidin peptides $(n)$ & 5 & 7 & 2 & 4 & & & \\
\hline $\mathrm{Hyp}^{3}-\mathrm{KBK}+\mathrm{KBK}-(1-7)(\mathrm{pmol} / \mathrm{l})$ & $0.6 \pm 0.1$ & $0.6 \pm 0.1$ & $0.8 \pm 0.4$ & $0.6 \pm 0.1$ & NS & NS & NS \\
\hline $\mathrm{Hyp}^{3}-\mathrm{KBK}+\mathrm{KBK}-(1-8)(\mathrm{pmol} / \mathrm{l})$ & $0.8 \pm 0.1$ & $0.8 \pm 0.1$ & $1.0 \pm 0.4$ & $0.8 \pm 0.2$ & NS & NS & NS \\
\hline $\mathrm{Hyp}^{3}-\mathrm{KBK}+\mathrm{KBK}-(1-9)(\mathrm{pmol} / \mathrm{l})$ & $0.5 \pm 0.1$ & $0.5 \pm 0.1$ & $0.9 \pm 0.5$ & $0.7 \pm 0.3$ & NS & NS & NS \\
\hline Tested for kininogens $(n)$ & 16 & 21 & 8 & 7 & & & \\
\hline LMWK (nmol/l) & $2519 \pm 125$ & $2505 \pm 87$ & $2145 \pm 141$ & $2534 \pm 117$ & NS & NS & NS \\
\hline HMWK (nmol/1) & $416 \pm 70$ & $471 \pm 61$ & $511 \pm 93$ & $353 \pm 59$ & NS & NS & NS \\
\hline Total kininogen $(\mathrm{nmol} / \mathrm{l})$ & $2935 \pm 152$ & $2976 \pm 90$ & $2656 \pm 155$ & $2887 \pm 140$ & NS & NS & NS \\
\hline Tested for kallikreins and kallistatin $(n)$ & 7 & 9 & 7 & 6 & & & \\
\hline Plasma kallikrein (\% control) & $100 \pm 8$ & $93 \pm 19$ & $107 \pm 31$ & $145 \pm 29$ & NS & NS & NS \\
\hline Tissue kallikrein ( $\%$ control) & $100 \pm 12$ & $90 \pm 12$ & $170 \pm 22$ & $139 \pm 18$ & 0.001 & NS & NS \\
\hline Kallistatin (\% control) & $100 \pm 4$ & $97 \pm 6$ & $119 \pm 12$ & $101 \pm 11$ & NS & NS & NS \\
\hline
\end{tabular}

Data shown as means \pm SEM. Non-hydroxylated and hydroxylated kinin peptides were summed to simplify data presentation

Ang, angiotensin; BK, bradykinin; LMWK, low molecular weight kininogen

ity in atrial myocytes and increased tissue kallikrein mRNA levels in atrial tissue. Increased tissue kallikrein levels in diabetic patients were not associated with altered circulating levels of bradykinin or kallidin peptides, plasma kininogens, plasma kallikrein or kallistatin. Blood bradykinin, kallidin and kininogen levels provided a measure of the activity of the KKS. Moreover, the failure of diabetes to influence blood kallidin and kininogen levels, despite increased tissue kallikrein levels, was consistent with the predominant tissue localisation of tissue kallikrein, where it may participate in local formation of kallidin peptides. Our finding that tissue kallikrein was produced by atrial myocytes was in agreement with the previous identification of tissue kallikrein mRNA in rat heart and the immunolocalisation of tissue kallikrein to rat atrial myocytes [23].

Non-diabetic and diabetic patients were well matched in our study and although abdominal circumference was not measured, non-diabetic and diabetic patients had similar BMI and prevalence of metabolic syndrome features, as well as similar insulin sensitivity and insulin resistance. Our data therefore indicate an effect of diabetes as such on tissue kallikrein gene expression, rather than solely an effect of insulin resistance.
Our finding of similar blood kinin levels in non-diabetic and diabetic patients argues against a role for kinin peptides in the endothelial dysfunction of type 2 diabetes [24]. Moreover, the lack of effect of statin therapy on any
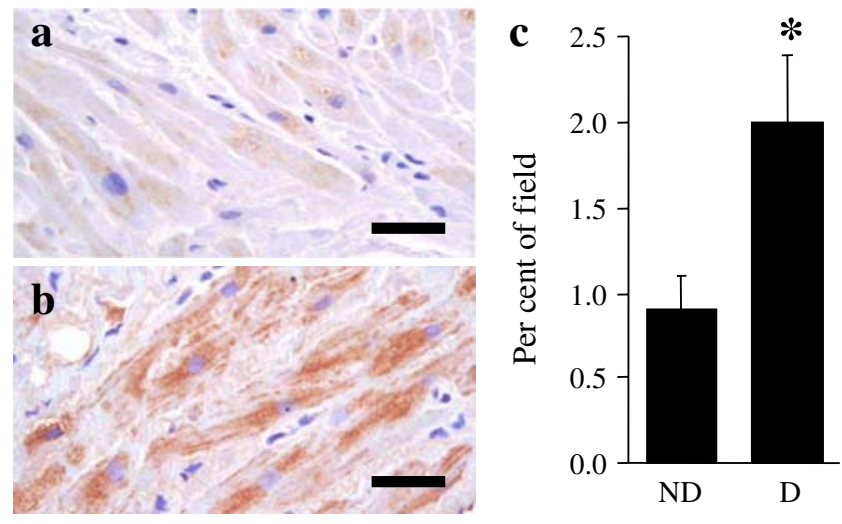

Fig. 1 Immunostaining for tissue kallikrein in atrial tissue from nondiabetic (a) or diabetic (b) group 2 patients. Immunostaining was performed with polyclonal antibody anti-TproK-AS raised against recombinant human tissue prokallikrein. This antibody recognises tissue prokallikrein and active tissue kallikrein. Scale bar, $20 \mu \mathrm{m}$. c Quantification of immunohistochemical staining as per cent area $($ mean \pm SEM) for seven non-diabetic (ND) and five diabetic (D) patients. ${ }^{*} p=0.015$ 
variable of the circulating KKS suggests that the KKS does not play a role in mediating the improvement of endothelial function by statin therapy in non-diabetic and diabetic patients $[11,12]$. Our finding that statin therapy was associated with decreased plasma aldosterone levels was in agreement with a previous study [25] and may have been due to an effect of statins on cholesterol supply for steroid hormone synthesis [26], although we cannot exclude a possible association between statin therapy and altered electrolyte intake.

The mechanism of increased tissue kallikrein gene expression in type 2 diabetes is uncertain. Mineralocorticoid administration increases plasma levels of tissue kallikrein [27]. However, our finding of similar plasma aldosterone levels in non-diabetic and diabetic patients suggests that altered aldosterone levels did not contribute to the increased tissue kallikrein gene expression in diabetic patients. Importantly with regard to type 2 diabetes, insulin administration to non-diabetic rats increased renal kallikrein content and renal kallikrein synthesis, accompanied by a similar proportional increase of total protein synthesis in the kidney [28]. It is therefore possible that the increased tissue kallikrein gene expression in type 2 diabetes observed in the present study was caused by hyperinsulinaemia. Although we were unable to show an increase in fasting plasma insulin levels in diabetic patients, it is likely that they had higher postprandial insulin levels. Further evidence for an effect of insulin on the KKS is the reduction in plasma HMWK levels during insulin administration to nondiabetic human volunteers, consistent with increased HMWK cleavage by either plasma or tissue kallikrein [17].

One potential limitation was that we studied patients with coronary artery disease who were scheduled for CABG surgery. Coronary artery disease, however, is a frequent accompaniment of type 2 diabetes. Another limitation was the relatively low number of patients for some of the KKS variables measured in this study, possibly providing insufficient statistical power to demonstrate effects of diabetes or statin therapy.

In summary, we found increased tissue kallikrein levels in type 2 diabetes, but no effect of statin therapy on the KKS. Given the essential role of tissue kallikrein in protecting the heart from ischaemic injury [2, 3], our finding that tissue kallikrein levels were increased in type 2 diabetes suggests tissue kallikrein may play a greater role in cardioprotection in type 2 diabetic than in non-diabetic patients and may also contribute to the benefits that type 2 diabetic patients derive from ACE inhibitor and other therapies inhibiting kinin metabolism. Our findings do not support the idea that the KKS plays a role in the impaired endothelial function of type 2 diabetes or in mediating the improvement of endothelial function by statin therapy in non-diabetic and diabetic patients.
Acknowledgements $\mathrm{We}$ are grateful to A. Januszewski, C. Karschimkus and K. Davis for assistance with measurement of carboxymethyl lysine and LMWF levels. This work was funded by grants from the National Health and Medical Research Council of Australia and from the National Heart Foundation of Australia. D. J. Campbell (Grant ID 395508) and D. J. Kelly (Grant ID 566867) are recipients of Senior Research Fellowships from the National Health and Medical Research Council of Australia.

Duality of interest The authors declare that there is no duality of interest associated with this manuscript.

\section{References}

1. Campbell DJ (2001) The kallikrein-kinin system in humans. Clin Exp Pharmacol Physiol 28:1060-1065

2. Spillmann F, van Linthout S, Schultheiss HP, Tschope C (2006) Cardioprotective mechanisms of the kallikrein-kinin system in diabetic cardiopathy. Curr Opin Nephrol Hypertens 15:22-29

3. Pizard A, Richer C, Bouby N et al (2008) Genetic deficiency in tissue kallikrein activity in mouse and man: effect on arteries, heart and kidney. Biol Chem 389:701-706

4. Marre M, Jeunemaitre X, Gallois Y et al (1997) Contribution of genetic polymorphism in the renin-angiotensin system to the development of renal complications in insulin-dependent diabetes. J Clin Invest 99:1585-1595

5. Huang W, Gallois Y, Bouby N et al (2001) Genetically increased angiotensin I-converting enzyme level and renal complications in the diabetic mouse. Proc Natl Acad Sci USA 98:13330-13334

6. Zeitz CJ, Campbell DJ, Horowitz JD (2003) Myocardial uptake and biochemical and hemodynamic effects of ACE inhibitors in humans. Hypertension 41:482-487

7. Heart Outcomes Prevention Evaluation (HOPE) Study Investigators (2000) Effects of ramipril on cardiovascular and microvascular outcomes in people with diabetes mellitus: results of the HOPE Study and MICRO-HOPE Substudy. Heart Outcomes Prevention Evaluation Study Investigators. Lancet 355:253-259

8. Lewis EJ, Hunsicker LG, Clarke WR et al (2001) Renoprotective effect of the angiotensin-receptor antagonist irbesartan in patients with nephropathy due to type 2 diabetes. N Engl J Med 345:851860

9. Campbell DJ, Krum H, Esler MD (2005) Losartan increases bradykinin levels in hypertensive humans. Circulation 111:315320

10. Campbell DJ, Kelly DJ, Wilkinson-Berka JL, Cooper ME, Skinner SL (1999) Increased bradykinin and "normal" angiotensin peptide levels in diabetic Sprague-Dawley and transgenic (mRen2)27 rats. Kidney Int 56:211-221

11. John S, Schlaich M, Langenfeld $M$ et al (1998) Increased bioavailability of nitric oxide after lipid-lowering therapy in hypercholesterolemic patients: a randomized, placebo-controlled, double-blind study. Circulation 98:211-216

12. Wilson SH, Simari RD, Best PJ et al (2001) Simvastatin preserves coronary endothelial function in hypercholesterolemia in the absence of lipid lowering. Arterioscler Thromb Vasc Biol $21: 122-128$

13. Levey AS, Bosch JP, Lewis JB, Greene T, Rogers N, Roth D (1999) A more accurate method to estimate glomerular filtration rate from serum creatinine: a new prediction equation. Modification of Diet in Renal Disease Study Group. Ann Intern Med 130:461-470

14. Wallace TM, Levy JC, Matthews DR (2004) Use and abuse of HOMA modeling. Diabetes Care 27:1487-1495 
15. Januszewski AS, Thomas MC, Chung SJ et al (2005) Plasma lowmolecular weight fluorescence in type 1 diabetes mellitus. Ann NY Acad Sci 1043:655-661

16. Duncan A-M, Kladis A, Jennings GL, Dart AM, Esler M, Campbell DJ (2000) Kinins in humans. Am J Physiol Regul Integr Comp Physiol 278:R897-R904

17. Rothschild AM, Boden G, Colman RW (1996) Kininogen changes in human plasma following a test meal or insulin administration. Am J Physiol Heart Circ Physiol 270:H1071-H1077

18. Veloso D, Silver LD, Hahn S, Colman RW (1987) A monoclonal anti-human plasma prekallikrein antibody that inhibits activation of prekallikrein by factor XIIa on a surface. Blood 70:1053-1062

19. Veloso D, Colman RW (1991) Western blot analyses of prekallikrein and its activation products in human plasma. Thromb Haemost 65:382-388

20. Chao JL, Schmaier A, Chen LM, Yang ZR, Chao L (1996) Kallistatin, a novel human tissue kallikrein inhibitor: levels in body fluids, blood cells, and tissues in health and disease. J Lab Clin Med 127:612-620

21. Kemme M, Podlich D, Raidoo DM, Snyman C, Naidoo S, Bhoola KD (1999) Identification of immunoreactive tissue prokallikrein on the surface membrane of human neutrophils. Biol Chem 380:1321-1328
22. Barth AS, Merk S, Arnoldi E et al (2005) Reprogramming of the human atrial transcriptome in permanent atrial fibrillation: expression of a ventricular-like genomic signature. Circ Res 96:1022-1029

23. Xiong W, Chen L-M, Woodley-Miller C, Simson JA, Chao J (1990) Identification, purification, and localization of tissue kallikrein in rat heart. Biochem J 267:639-646

24. Williams SB, Cusco JA, Roddy MA, Johnstone MT, Creager MA (1996) Impaired nitric oxide-mediated vasodilation in patients with non-insulin-dependent diabetes mellitus. J Am Coll Cardiol 27:567-574

25. Ide H, Fujiya S, Aanuma Y, Agishi Y (1990) Effects of simvastatin, an $\mathrm{HMG}-\mathrm{CoA}$ reductase inhibitor, on plasma lipids and steroid hormones. Clin Ther 12:410-420

26. Campbell DJ (1982) Effect of rat plasma lipoproteins on aldosterone production by rat zona glomerulosa cells in vitro. $\mathrm{J}$ Steroid Biochem 17:709-711

27. Ohman KP (1997) Circulating kallikreins in normotensive and hypertensive humans: effects of mineralocorticoid administration. Blood Press 6:214-222

28. Jaffa AA, Miller DH, Bailey GS, Chao J, Margolius HS, Mayfield RK (1987) Abnormal regulation of renal kallikrein in experimental diabetes: effects of insulin on prokallikrein synthesis and activation. J Clin Invest 80:1651-1659 